\title{
Study on Corrosion Behavior of Cast Iron in the Snowmelt Agent Environment
}

\author{
Yan WANG ${ }^{1, \mathrm{a}}$,Yan $\mathrm{LIU}^{1, \mathrm{~b}}$, Xin ZHOU ${ }^{1, \mathrm{c}}$,Yan $\mathrm{ZHAO}^{1, \mathrm{~d}}$
}

${ }^{1}$ The Liaoning Key Lab of Optimization and Utilization of Non-associated Low

grade Iron Ore in Benxi, Liaoning Province, Liaoning Institute of Science and Technology, Liaoning, Benxi, China

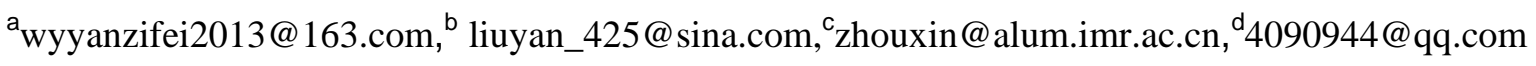

Keywords: corrosion, HT250, snowmelt agent, industrial salt, environment-friendly snowmelt agent.

\begin{abstract}
The corrosion behavior of HT250 which mainly used for automobile chassis materials is introduced in this paper, it was soaked in industrial salt solution and environment-friendly snowmelt agent solution of different concentrations, the relationships of the degree of corrosion on the surface of the cast iron with the soaking time and concentration of snowmelt agent are discussed respectively, in order to provide the basis that further improve the corrosion resistance of cast iron on vehicle, improve its service life.
\end{abstract}

\section{Introduction}

The snowmelt agent is usually used to clean the road after snow. Because the chlorine salt in the snowmelt agent can reduce the freezing point of the system ${ }^{[1]}$. But the chlorine salt has harm to the environment. In the past, the research focused on its corrosion damage to roads, bridges and other infrastructure. The vehicle traveling after snow will be splashed large amounts of snow-broth with snowmelt agent into the vehicle chassis, engine, exhaust pipe, door, braking system, etc, among these metal components which are made by cast iron, it may cause the vehicle corrosion and damage, reduce the service life of the car, or even accidents.

\section{Experiment Methods}

\subsection{The raw material}

HT250 material mainly used for automobile chassis is adopts as this experiment research object; the composition is shown in table 1.

Table 1 HT250 component.

\begin{tabular}{|c|c|c|c|c|c|}
\hline Component & C & Si & Mn & P & S \\
\hline Content (\%) & $3.16-3.30$ & $1.79-1.93$ & $0.98-1.04$ & $0.120-1.170$ & $0.094-0.125$ \\
\hline
\end{tabular}

The industrial salt and environment-friendly snowmelt agent which are the commercially available commonly used snowmelt agents are studied in this research. Industrial salt is composed of hydrochloric acid, caustic soda, soda ash, ammonium chloride, chlorine and other synthetic, which is a kind of commonly used snowmelt agent. Environment-friendly snowmelt agent is given priority to sodium chloride, also contains a small amount of calcium chloride, magnesium chloride, potassium chloride, etc. ${ }^{[2]}$.

\subsection{Experiment method}

The HT250 is made into $50 \times 10 \times 6 \mathrm{~mm}$ samples. The two kinds of snowmelt agent solution concentration was $1.0 \%, 1.5 \%, 2.0 \%, 2.5 \%, 3.0 \%$ respectively. The cast iron sample dipping in different concentrations of industrial salt solution are record as from No.1 sample to No.5 sample. The cast iron sample dipping in different concentrations of environment-friendly snowmelt agent solution are record as from No.6 sample to No.10 sample. 
Weightlessness experiment method was used. The samples after grinding, washing, dehydration, weighing, will be dipped into the snowmelt agent solution in different concentration and the beaker will be sealed ${ }^{[3]}$. The sample will be removed and weighed every $24 \mathrm{~h}$; this process will be for five days in a row. The weightlessness ratio will be calculated with the measured data, the computation formula is as follows:

$$
\begin{gathered}
\alpha=\left(\mathrm{m}_{0}-\mathrm{m}\right) / \mathrm{m}_{0} \times 100 \% \\
\alpha \text { - weightlessness ratio }(\%) \\
\left.\mathrm{m}_{0} \text { - original mass } \mathrm{g}\right) \\
\mathrm{m} \text { - the mass of some day }
\end{gathered}
$$

\section{Results and discussion}

\subsection{The influence of soaking time on cast iron corrosion resistance}

In industrial salt solution and environment-friendly snowmelt agent solution, the relationship of cast iron corrosion weightless ratio with time is shown in figure 1.

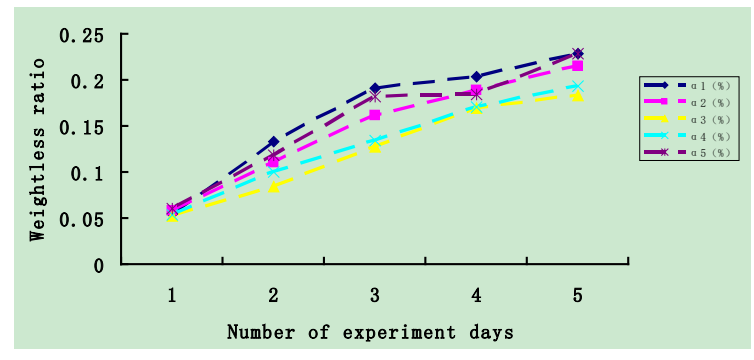

a

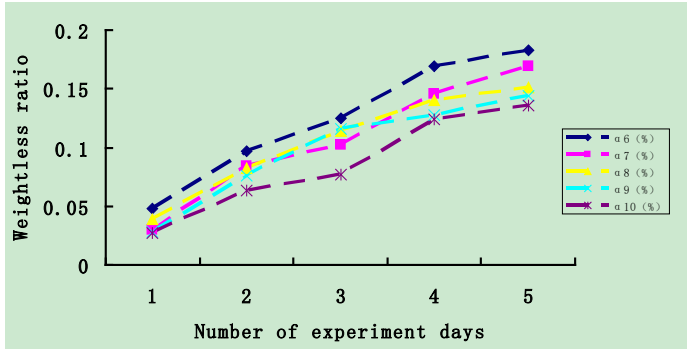

$\mathrm{b}$

Figure 1 Relationship of weightless ratio with time.

a industrial salt solution , b environment-friendly snowmelt agent solution.

As shown in figure 1, the samples are obviously corrosion occurred both in industrial salt solution and environment-friendly snowmelt agent solution. Under the same condition, the change tendency of the weightless ratio are basically same, the corrosion degree is increase with the time.

\subsection{The influence of snowmelt agent concentration on cast iron corrosion resistance}

In industrial salt solution and environment-friendly snowmelt agent solution, the relationship of cast iron corrosion weightless ratio with snowmelt agent concentration is shown in figure 2 .

As shown in figure 2, at the same day, in industrial salt solution, the lightest corrosion degree of deicing salt concentration was 2.0\%, the heaviest was $1.0 \%$. In Environment-friendly snowmelt agent solution, the lightest corrosion degree of deicing salt concentration was $3.0 \%$, the heaviest was $1.0 \%$, at the same day.

\subsection{The comparison between chlorine salt snowmelt agent and environment-friendly snowmelt agent}

Base on the conclusion of figure 1 and 2, they are shown that the corrosion degrees of samples are lightest, when the concentration of industrial salt is $2.0 \%$ and the concentration of environmentfriendly snowmelt agent is $3.0 \%$. Therefore the two concentration snowmelt agent solutions are comparatively studied. The results are shown in figure 3.

As shown in figure 3 , the curve 3 is always above the curve 10; hence the corrosion of cast iron by environment-friendly snowmelt agent is lighter than by the industrial salt solution, when their corrosion is the lightest. 


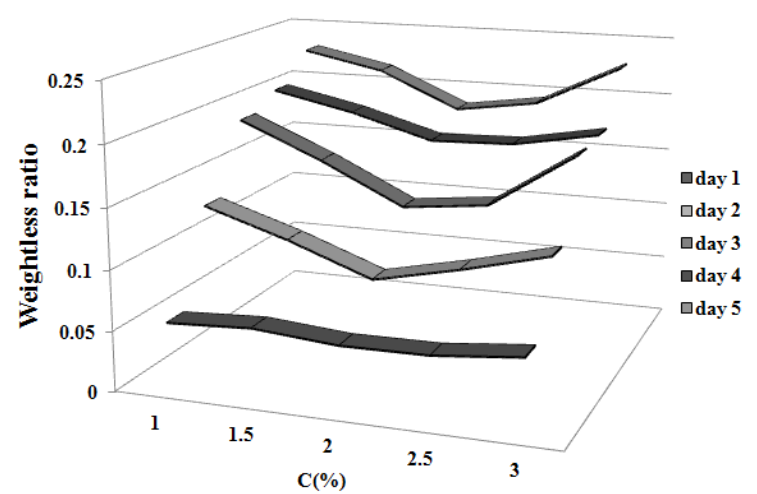

$\mathrm{a}$

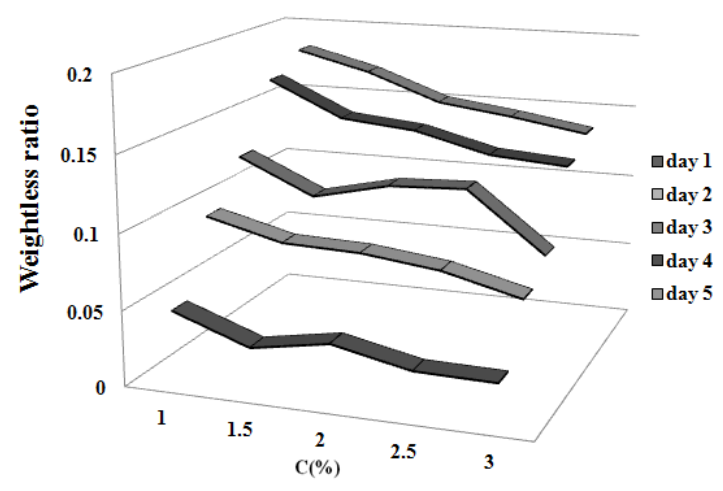

$\mathrm{b}$

Figure 2 Relationship of weightless ratio with concentration. a industrial salt solution, b environment-friendly snowmelt agent solution.

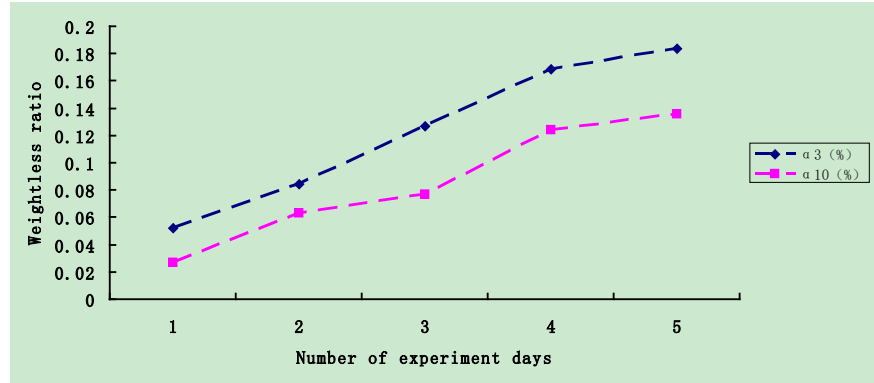

Figure 3 the influence of snowmelt agent type on the corrosion of the cast iron.

After snowmelt agent dissolved in the water, the $\mathrm{Cl}^{-}$can destroy the passivation membrane on the surface of the cast iron. Under the effect of electrolyte, anode generated corrosion in the area of iron to occur $\mathrm{Fe}^{2+}$. The chloride ion migrates, enrich continuously to anode area under the effects of the electric field in a corrosion cell. $\mathrm{Fe}^{2+}$ and $\mathrm{Cl}^{-}$generate $\mathrm{FeCl}_{2}$ soluble in water, and then spread to the anode zone, which generated commonly known as brown rust $\mathrm{Fe}(\mathrm{OH})_{2}$ with $\mathrm{OH}^{-}$of cathode region, $\mathrm{Fe}(\mathrm{OH})_{2}$ was further oxidation generated $\mathrm{Fe}(\mathrm{OH})_{3}$, after dehydration, $\mathrm{Fe}(\mathrm{OH})_{3}$ become loose, porous and incoherent red rust $\mathrm{Fe}_{2} \mathrm{O}_{3}$; under the condition of less oxygen, $\mathrm{Fe}(\mathrm{OH})_{2}$ oxidation is not very completely, part forming black rust $\mathrm{Fe}_{3} \mathrm{O}_{4}$. After $\mathrm{Fe}(\mathrm{OH})_{2}$ generated, the $\mathrm{Cl}^{-}$ is released, the $\mathrm{Cl}^{-}$will migrate to the anode area again. More $\mathrm{Fe}^{2+}$ will be bring out and not used up in the corrosion process, so it have catalytic effect on the corrosion. That is can be seen the effect of $\mathrm{Cl}^{-}$on anode to corrosion of cast iron is depolarization, to accelerate cast iron anode reactions, to promote local corrosion of cast iron ${ }^{[4,5]}$. Equation is as follows:

Anode:

$$
\mathrm{Fe}^{2+}+\mathrm{Cl}^{-} \rightarrow\left[\mathrm{FeCl}_{2}\right]^{2-}
$$

$\mathrm{FeCl}_{2}$ enters into the solution easily and ionizes:

$$
\begin{array}{r}
{\left[\mathrm{FeCl}_{2}\right]^{2-}-2 \mathrm{e} \rightarrow \mathrm{FeCl}_{2}} \\
\mathrm{FeCl}_{2} \rightarrow \mathrm{Fe}^{2+}+\mathrm{Cl}^{-}
\end{array}
$$

The cathode oxygen depolarization process:

Cathode: 


$$
\mathrm{O}_{2}+2 \mathrm{H}_{2} \mathrm{O}+4 \mathrm{e} \rightarrow 4 \mathrm{OH}^{-}
$$

Hence $\mathrm{Fe}(\mathrm{OH})_{2}$ is generated by $\mathrm{Fe}^{2+}$ and $\mathrm{OH}^{-}$in solution.

$\mathrm{Fe}(\mathrm{OH})_{2}$ reacts with dissolved oxygen in the water to generated $\mathrm{Fe}(\mathrm{OH})_{3}$ again.

$$
4 \mathrm{Fe}(\mathrm{OH})_{2}+\mathrm{O}_{2}+2 \mathrm{H}_{2} \mathrm{O} \rightarrow \mathrm{Fe}(\mathrm{OH})_{3}
$$

Therefore with the increase of time, $\mathrm{Cl}^{-}$internal migration quantity to cast iron increases, that the reaction $(2) \sim(6)$ process is exacerbated the erosion quantity of cast iron is increased.

According to figure 2, in industrial salt solution, the lightest corrosion degree of snowmelt agent concentration was $2.0 \%$, the heaviest was $1.0 \%$. This may be due to in industrial salt solution snowmelt agent when the concentration was $2.0 \%$, the diffusion speed of $\mathrm{Cl}^{-}$is less than the generating speed of $\mathrm{Fe}(\mathrm{OH})_{2}$, so the $\mathrm{Fe}(\mathrm{OH})_{2}$ generated played a protective effect on cast iron surface, reduce erosion degree of chloride salt solution to the cast iron. When snowmelt agent concentration was $1.0 \%$, the spread of the $\mathrm{Cl}^{-}$faster than $\mathrm{Fe}(\mathrm{OH})_{2}$ generating speed, so the generated $\mathrm{Fe}(\mathrm{OH})_{2}$ can't well cover the surface of cast iron, the $\mathrm{Cl}^{-}$further reacts with iron of the cast iron surface, which exacerbated corrosion. For environment-friendly snowmelt agent, the lightest corrosion degree of deicing salt concentration was $3.0 \%$, the heaviest was $1.0 \%$. It may be that in high concentration solution, the corrosion products $\mathrm{Fe}(\mathrm{OH})_{2}$ that formed on the cast iron surface turn into $\mathrm{Fe}(\mathrm{OH})_{3}$ more slowly, and not easy to fall off, thus form a thicker protective layer, which can hinder the $\mathrm{Cl}^{-}$diffusion and erosion better.

Adopting environment-friendly snowmelt agent, after the corrosion of cast iron, a layer of thick corrosion products protective film is formed on the cast iron surface, which hindered the $\mathrm{Cl}^{-}$further to diffuse on the cast iron surface. So the corrosion product layer is thickening with the increase of time, the corrosion of cast iron due to snowmelt agent solution decreases. For the industrial salt solution, the corrosion product of cast iron is easy to fall off, so that the cast iron surface is bare, it will direct contact with the solution, which cause the surface of cast iron have been corrosion, the weightlessness ratio fluctuates up and down, and always higher than that of environment-friendly snowmelt agent. It also can be seen in figure 4 (scanning electron microscopy pictures, ZEISS EVO18), that the corrosion surface of the cast iron in industrial salt snowmelt agent solution, the corrosion product layer is thinner, and the corrosion product layer in environment-friendly snowmelt agent is thicker, the conclusion of figure 3 is also proved.

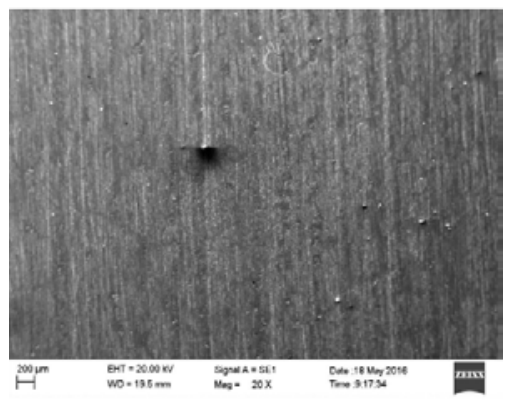

$\mathrm{a}$

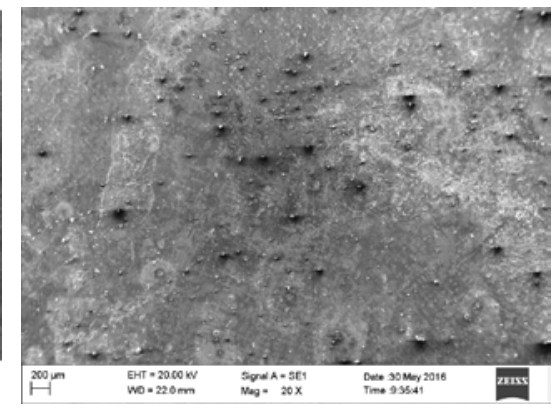

b

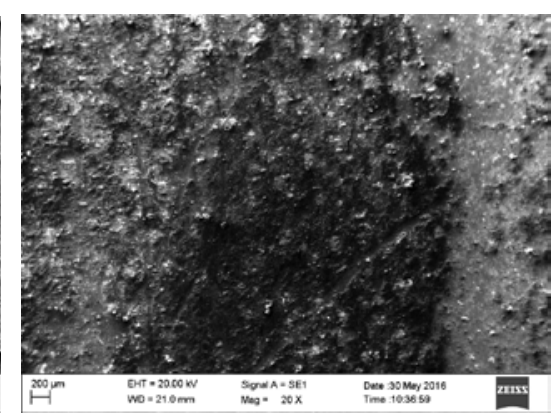

C

Figure 4 Corrosion morphology

a Without any processing, b when the concentration of chlorine salt solution is $2.0 \%$, c when the concentration of environment-friendly snowmelt agent solution is $3.0 \%$

\section{Conclusions}

(1) At the same concentration of snowmelt agent, with the increase of reaction time, cast iron surface corrosion is more and more serious.

(2) In this experiment, the corrosion rate is least at $2.0 \%$ concentration industrial salt snowmelt agent, and $3.0 \%$ is the largest. Therefore, the appropriate industrial salt content is $2.0 \%$, which can 
reduce the corrosion of vehicles, and can also save costs.

(3)The decrease of weightlessness ratio for environment-friendly snowmelt agent solution is less than that of industrial salt solution; this is because a layer of thick corrosion products protective film is formed on the cast iron surface, which hindered the $\mathrm{Cl}$ - further to diffuse on the cast iron surface.

\section{Acknowledgements}

This paper was supported by Liaoning Province Doctor Startup Fund (No. 1511311) and the innovation team of green metallurgy and resource comprehensive utilization for financial support.

\section{References}

[1] Peng TAO. (2007) The study of Snowmelt agent corrosion of carbon steel. Bei Jing. 1-5.

[2] Ying-Ying ZHAO. (2006) The research of chemical snowmelt agent to environmental impact. Chang Chun. 1-3.

[3] John J. Myers, Wei Zheng. (2011)Modern Protection Systems to Prevent Corrosion of Structural Steel Elementsdue to Deicing and Roadway Salts,.Geohunan International Conference, 121-128.

[4] K.Honjo,N.Fujiwara. (2012) Investigation of Deteriorated RC Slabs on Steel Girder by Chloride Attack of Snowmelt agent. Third International Conference on Sustainable Construction Materials and Technologies, 1-9.

[5] Dong-Mei WANG, Yi DONG, Zhen-Qian ZHOU, Chun YANG, Yan-Yong ZHU(2010) Investigations on the mechanism of iron and steel corrosions in chloride salts environment. Metallurgical Analysis, 1012--1015. 